\title{
Treatment for patients with multidrug resistant Acinetobacter baumannii pulmonary infection
}

\author{
TAO PAN, XIAOYUN LIU, SHOUGUI XIANG and WENLI JI \\ Department of Intensive Care Medicine, Xiangyang Hospital Affiliated to Hubei \\ University of Medicine, Xiangyang, Hubei 441000, P.R. China
}

Received October 6, 2015; Accepted February 8, 2016

DOI: 10.3892/etm.2016.3051

\begin{abstract}
Bacterial infections are common but have become increasingly resistant to drugs. The aim of the present study was to examine the combined treatment of traditional Chinese and Western medicine in 30 cases of pulmonary infection with multidrug resistant Acinetobacter baumannii. Patients were divided into groups $\mathrm{A}$ and $\mathrm{B}$ according to drug treatments. Cefoperazone or sulbactam and tanreqing were administered in group $\mathrm{A}$, and cefoperazone or sulbactam in group B. The curative effect and prognosis of the two groups were recorded and the remaining treatments were performed routinely in the clinic. For the combined therapy group, which was administered sulperazone and tanreqing, 8 patients were recovered, 6 patients had significant effects, 3 patients exhibited some improvement and 1 patient had no response. One of the patients did not survive after 28 days. By contrast, there were 4 patients that were successfully treated, 3 patients with significant effects, 2 patients with some improvement and 2 patients had no response in the sulperazone group, and 4 patients did not survive after 28 days. In conclusion, the combined therapy of cefoperazone or sulbactam supplemented with tanreqing was identified to be more effective than cefoperazone or sulbactam as monotherapy, for treating multidrug resistant Acinetobacter baumannii.
\end{abstract}

\section{Introduction}

The extensive use of antibiotics and the gradual increase of different types of drugs have made bacteria resistant to drugs $(1,2)$. Appropriate selection of antibiotics for the treatment of the majority of severe microbial infections. The emerging resistance of different pathogenic microbes to drugs

Correspondence to: Dr Xiaoyun Liu, Department of Intensive Care Medicine, Xiangyang Hospital Affiliated to Hubei University of Medicine, 15 Jiefang Road, Xiangyang, Hubei 441000, P.R. China

E-mail: damoxp@163.com

Key words: acinetobacter, pulmonary infection, sulperazone, tanreqing refers to multidrug-resistant, extensively drug-resistant or pandrug-resistant bacteria.

The drug resistance of acinetobacter is more severe due to the emergence of pan-resistant Acinetobacter baumannii, which is pan-resistant to antibacterial agents in current routine testing $(3,4)$. Consequently, the treatment of pan-resistant Acinetobacter baumannii has become a worldwide issue. Pan-resistant, Acinetobacter baumannii is defined as the bacterial strain that is pan-resistant to common anti-gram-negative antibiotics such as penicillin, cephalosporin, monocyclic lactams, aminoglycosides, quinolones, carbapenems, tetracyclines and sulfonamides (5).

To circumvent infections caused by this infectious bacteria, Xiangyang Hospital has applied combined treatment of traditional Chinese and Western medicine to pan-resistant Acinetobacter baumannii cases in intensive care unit patients during the period January 1, 2008 to December 31, 2009, which has achieved promising effects. The present study examined the effect of the combined therapy of sulperazone supplemented with tanreqing, and sulperazone, as monotherapy.

\section{Materials and methods}

Patients. The present study included 30 patients suffering from pulmonary infection with pan-resistant Acinetobacter baumannii in the Xiangyang Hospital during the period January 1, 2008 to December 31, 2009.

Microbiological methods. Clinical samples were collected aseptically. The sputum specimens were taken through the artificial airway and a drug sensitivity test was performed according to the agar diffusion method to determine their sensitivity to 19 antibacterial drugs.

Clinical data. The extracted pan-resistant Acinetobacter baumannii was observed immediately and was divided into colonized bacteria and infectious bacteria according to the hospital infection diagnostic criteria established by the Ministry of Health. The extracted bacterium was defined as colonized bacteria if it did not qualify for the diagnostic criteria (6).

The treatment effects of groups A and B were retrospectively analyzed. The antibacterial drugs employed in group A were a combination of cefoperazone, sulbactam (Pfizer, NY, USA) and tanreqing (Kangbao, Shanxi,China). Cefoperazone 
( $2 \mathrm{~g})$ and sulbactam ( $3 \mathrm{~g})$ were administered by intravenous drip every $8 \mathrm{~h}$. Tanreqing $(20 \mathrm{ml})$ was then added into the intravenous drip once a day. For group B, the cases were treated with only cefoperazone and sulbactam. The curative effect and prognosis of the two groups were recorded and the remaining treatments were administered as per clinical routine. The effects were evaluated based on the guiding principles of clinical research on antibacterial agents, as established released by the Ministry of Health (7). The main criteria for the clinical effects were symptom, sign and laboratory inspection. The 4 grades for assessment were: recovery, significantly improved, improved and no response. In addition, mortality within 28 days after infection was observed.

Statistical analysis. Enumeration data were carried out using the $\chi^{2}$ test for statistical analysis. $\mathrm{P}<0.05$ was considered to indicate a statistically significant difference.

\section{Results}

Treatment effects. Table I shows the outcomes for the two different drug treatments for Acinetobacter baumannii. For the sulperazone and tanreqing group, there were 8 recovered patients, 6 patients with significant effects, 3 patients with some improvement and 1 case with no response. In addition one patient succumbed after 28 days. By contrast, in the sulperazone-treated group there were 4 patients who were successfully treated, 3 patients with significant effects, 2 patients with some improvement and 2 patients with no response. Four patients succumbed after 28 days.

Comparison of the disappearing time of clinical symptoms between the two groups. After relieving the fever, the time period in which cough, phlegm, asthma, pulmonary rales and pulmonary shadow disappeared were compared between the two groups. Significant differences were identified $(\mathrm{P}<0.05$, Table II).

Adverse reactions. None of the patients exhibited skin rash or other allergic reactions during treatment. Liver and renal function, a urine routine examination, and ECG showed no significant changes prior to and following treatment.

\section{Discussion}

Since the establishment of the Xiangyang Hospital in 1992, we have observed the emergence of Acinetobacter baumannii and currently there are infection cases of pan-resistantAcinetobacter baumannii (8-10). The challenge for treating pulmonary infection with pan-resistant Acinetobacter baumannii involves
Table I. Comparison of treatment effects in the two groups.

\begin{tabular}{lcccc}
\hline Group & Cases & $\begin{array}{c}\text { Clinical } \\
\text { efficiency }\end{array}$ & $\begin{array}{c}\text { Mortality } \\
\text { in 28 days }\end{array}$ & P-value \\
\hline $\begin{array}{l}\text { Sulperazone }+ \\
\text { tanreqing }\end{array}$ & 15 & $68.4 \%$ & $6.66 \%$ & $<0.05$ \\
\begin{tabular}{l} 
Sulperazone \\
\hline
\end{tabular} & 15 & $45.0 \%$ & $26.66 \%$ & $<0.05$ \\
\hline
\end{tabular}

selection of medication (11). Previous findings have shown that cefoperazone sodium and sulbactam sodium, as well as minocycline and polymyxin are effective in terms of treating pan-resistant Acinetobacter baumannii (12-15). However, since polymyxin is no longer available, cefoperazone sodium and sulbactam sodium tanreqing were used in the present study to compare the effectiveness of the combination of the two drugs (16).

Drug resistance arises in pan-resistant Acinetobacter baumannii from several mechanisms, the most important of which are the production of many types of hydrolases, changing the affinity of antibiotics and penicillin-binding protein (PBP), and decreasing the permeability of the outer membrane of bacteria or active efflux. Thus, the production of many types of hydrolases has become the main resistance mechanism.

Sulbactam inhibits many different types of $\beta$-lactamases (TEM1, TEM2 and SHV1) and most extended spectrum of $\beta$-lactamases are produced by bacteria in order to manage many bacteria resistant to hydrolase $(17,18)$. It can have direct effects on PBP2 of bacteria and can enhance the sensitivity by $60-100 \%$. There is also a direct correlation between its bacteriostasis and drug concentration. Cefoperazone and sulbactam have synergistic effects on $61 \%$ of the acinetobacter bacterial strain and have additive effects on $39 \%$ of acinetobacter bacterial strain, which can fully present its unique bactericidal effects on acinetobacter (19).

As an efficient, low toxicity and safe new traditional Chinese medicine, tanreqing is composed of radix scutellariae, bear bile powder, cornu gorais, honeysuckle and fructus forsythiae and has beneficial roles for clearing heat, detoxicating and resolving phlegm. The honeysuckle and fructus forsythiae in tanreqing can inhibit and disinfect many pathogenic microorganisms, as well as increase the anti-inflammatory effects of neutrophil and macrophage. This improves the content of serum lytic enzyme and enhances the immune mechanism (20-22). Furthermore, tanreqing improves Th1- and Th2-cell function and promotes the immunity of body cells and fluids. Moreover, tanreqing has significant inhibitory effects on the increase of centric fever medium prostaglandin E2 and cyclic adenosine

Table II. Comparison of the time period clinical symptoms terminated between the two groups (day, mean \pm standard deviation).

\begin{tabular}{lccccc}
\hline Group & $\begin{array}{c}\text { Patient } \\
\text { no. }\end{array}$ & $\begin{array}{c}\text { Fever } \\
\text { relieving }\end{array}$ & $\begin{array}{c}\text { Time cough, phlegm, } \\
\text { asthma terminated }\end{array}$ & $\begin{array}{c}\text { Time pulmonary } \\
\text { rales terminated }\end{array}$ & $\begin{array}{c}\text { Time shadow } \\
\text { terminated }\end{array}$ \\
\hline Sulperazone + tanreqing & 15 & $2.42 \pm 0.87$ & $5.47 \pm 2.17$ & $4.37 \pm 1.53$ & $7.22 \pm 1.56$ \\
Sulperazone & 15 & $2.92 \pm 1.02$ & $7.13 \pm 3.03$ & $6.05 \pm 1.86$ & $8.69 \pm 2.25$ \\
\hline
\end{tabular}


monophosphate and hypersensitivity process of immune cells $(23,24)$. Tanreqing has bacteriostasis effects on 10 common bacteria such as Staphylococcus aureus, Staphylococcus epidermidis, $\beta$-hemolytic Streptococcus, Haemophilus influenzae, Pseudomonas aeruginosa, Escherichia coli, Proteusbacillus vulgaris, K. pneamoniae, Mycoplasma and mycobacterium tuberculosis. In addition, tanreqing lowers the mortality of mice infected by Staphylococcus aureus and influenza virus (25).

In summary, the results have shown that sulperazone in combination with tanreqing is more effective in controlling pan-resistant Acinetobacter baumannii. The combined therapy of sulperazone and tanreqing has higher clinical efficiency (68.4\%) compared to the monotherapy of sulperazone (45\%). Additionally, the combination therapy enhances the survivability of infected patients with $6.66 \%$ of mortality rate compared to $26.6 \%$ with sulperazone alone. Thus, the combination therapy of sulperazone and tanreqing is recommended in the regulation of Acinetobacter baumannii-induced pan-resistance in hospitalized patients undergoing critical care.

\section{References}

1. El-Ageery SM and Al-Hazmi SS: Microbiological and molecular detection of VIM-1 metallo beta lactamase-producing Acinetobacter baumannii. Eur Rev Med Pharmacol Sci 18: 965-970, 2014

2. El-Ageery SM, Abo-Shadi MA, Alghaithy AA, Ahmad MA, Alsharif $\mathrm{NH}$ and Alharbi SA: Epidemiological investigation of nosocomial infection with multidrug-resistant Acinetobacter baumannii. Eur Rev Med Pharmacol Sci 16: 1834-1839, 2012.

3. López-Rojas R, Docobo-Pérez F, Pachón-Ibáñez ME, de la Torre BG, Fernández-Reyes M, March C, Bengoechea JA, Andreu D, Rivas L and Pachón J: Efficacy of cecropin A-melittin peptides on a sepsis model of infection by pan-resistant Acinetobacter baumannii. Eur J Clin Microbiol Infect Dis 30 1391-1398, 2011.

4. Shao BB and Feng HB: Successful treatment of pan-resistant Acinetobacter baumannii infection of the lung with tigecycline: a report of one case. Zhonghua Wei Zhong Bing Ji Jiu Yi Xue 25: 636, 2013 (In Chinese).

5. Magiorakos AP, Srinvasan A, Carey RB, Carmeli Y, Falagas ME, Giske CG, Harbarth S, Hindler JF, Kahlmeter G, OlssonLiljequist B, Paterson DL, Rice LB, Stelling J, Struelens MJ, Vatopoulos A, Weber JT and Monnet DL: Multidrug resistant extensively drug Resistant and paddrug-resistant bacteria: an international expert proptsal for interim standard definitions for acquired resistance. Clin Microbiol Infect 18: 268-281, 2012

6. Doi Y, Onuoha EO, Adams-Haduch JM, Pakstis DL, McGaha TL, Werner CA, Parker BN, Brooks MM, Shutt KA, Pasculle AW, et al: Screening for Acinetobacter baumannii colonization by use of sponges. J Clin Microbiol 49: 154-158, 2011.

7. Spellberg B and Talbot G: Recommended design features of future clinical trials of antibacterial agents for hospital-acquired bacterial pneumonia and ventilator-associated bacterial pneumonia. Clin Infect Dis 51 (Suppl 1): S150-S170. D, 2010.

8. Tekçe AY, Erbay A, Cabadak H, Yağcı S, Karabiber N and Şen S: Pan-resistant Acinetobacter baumannii mediastinitis treated successfully with tigecycline: a case report. Surg Infect (Larchmt) 12: 141-143, 2011.
9. Antunes LC, Imperi F, Minandri F and Visca P: In vitro and in vivo antimicrobial activities of gallium nitrate against multidrug-resistant Acinetobacter baumannii. Antimicrob Agents Chemother 56: 5961-5970, 2012.

10. Telang NV, Satpute MG, Dhakephalkar PK, Niphadkar KB and Joshi SG: Fulminating septicemia due to persistent pan-resistant community-acquired metallo- $\beta$-lactamase (IMP-1)-positive Acinetobacter baumannii. Indian J Pathol Microbiol 54: 180-182, 2011.

11. Vila-Farres X, Garcia de la Maria C, López-Rojas R, Pachón J Giralt E and Vila J: In vitro activity of several antimicrobial peptides against colistin-susceptible and colistin-resistant Acinetobacter baumannii. Clin Microbiol Infect 18: 383-387, 2012.

12. Prata-Rocha ML, Gontijo-Filho PP and Melo GB: Factors influencing survival in patients with multidrug-resistant Acinetobacter baumannii infection. Braz J Infect Dis 16: 237-241, 2012.

13. McConnell MJ, Rumbo C, Bou G and Pachón J: Outer membrane vesicles as an acellular vaccine against Acinetobacter baumannii. Vaccine 29: 5705-5710, 2011

14. Le Hello S, Falcot V, Lacassin F, Mikulski M and Baumann F: Risk factors for carbapenem-resistant Acinetobacter baumannii infections at a tertiary care hospital in New Caledonia, South Pacific. Scand J Infect Dis 42: 821-826, 2010.

15. Sun SM, Wang YY, Yao CJ, Li HL, Yu F, Zhang YL, Zhou H and Wang NP: Clinical characteristics and therapy of pan-drug resistant Acinetobacter baumannii infection. Nan Fang Yi Ke Da Xue Xue Bao 30: 2351-2353, 2359, 2010 (In Chinese).

16. Principe L, D'Arezzo S, Capone A, Petrosillo N and Visca P: In vitro activity of tigecycline in combination with various antimicrobials against multidrug resistant Acinetobacter baumannii. Ann Clin Microbiol Antimicrob 8: 18, 2009.

17. Lü Y, Li Y, Xue F, Zhang XZ, Hu YJ, Jin YF, Chu YZ, Hu ZD, Zhao JH, Pan SY, et al: Analysis of resistance tendency of bloodstream-infecting pathogens in China. Zhonghua Jie He He Hu Xi Za Zhi 36: 411-419, 2013 (In Chinese).

18. Taccone FS, Rodriguez-Villalobos H, De Backer D, De Moor V, Deviere J, Vincent JL and Jacobs F: Successful treatment of septic shock due to pan-resistant Acinetobacter baumannii using combined antimicrobial therapy including tigecycline. Eur J Clin Microbiol Infect Dis 25: 257-260, 2006.

19. Navon-Venezia S, Ben-Ami R and Carmeli Y: Update on Pseudomonas aeruginosa and Acinetobacter baumannii infections in the healthcare setting. Curr Opin Infect Dis 18: 306-313, 2005.

20. Ozdem B, Gürelik FC, Celikbilek N, Balıkçı H and Açıkgöz ZC: Antibiotic resistance profiles of Acinetobacter species isolated from several clinical samples between 2007-2010. Mikrobiyol Bul 45: 526-534, 2011 (In Turkish).

21. Kulkova N, Babalova M, Sokolova J and Krcmery V: First report of New Delhi metallo- $\beta$-lactamase-1-producing strains in Slovakia. Microb Drug Resist 21: 117-120, 2015.

22. Fica C A, Céspedes J I, Gompertz G M, Jalón V M, Sakurada ZA and Sáez LE: Intravenous colistin in the treatment of infections due to pan-resistant Gram negative bacilli. Rev Chilena Infectol 24: 360-367, 2007 (In Spanish).

23. Marimuthu K, Gunaselvam P, Aminur Rahman M, Xavier R, Arockiaraj J, Subramanian S, Yusoff FM and Arshad A: Antibacterial activity of ovary extract from sea urchin Diadema setosum. Eur Rev Med Pharmacol Sci 19: 1895-1899, 2015.

24. Karakoc C, Tekin R, Yeşilbağ Z and Cagatay A: Risk factors for mortality in patients with nosocomial Gram-negative rod bacteremia. Eur Rev Med Pharmacol Sci 17: 951-957, 2013.

25. Gao Z, Xing H, Sun H and Li H: Experiment study on the pathogenicity of Staphylococcus aureus in laboratory mice. Chin J Comp Med 13: 87-89, 2003. 